\title{
Global prevalence of metabolic syndrome among patients with type I diabetes mellitus: a systematic review and meta-analysis
}

\author{
Rebuma Belete ${ }^{1 *}\left(\mathbb{D}, Z^{2}\right.$ Zerihun Ataro ${ }^{1}$, Ahmedmenewer Abdu $^{1}$ and Merga Sheleme ${ }^{2}$
}

\begin{abstract}
Background: The presence of metabolic syndrome among diabetes patients is frequent and is associated with an increased incidence of chronic complications and mortality. Despite several studies have been conducted, there is no overall estimation on the prevalence of metabolic syndrome among type 1 diabetic patients. Therefore, this study aimed to estimate the pooled prevalence of metabolic syndrome among patients with type 1 diabetes mellitus.

Methods: Medline via PubMed, CINAHL, ScienceDirect, Ovid, Google Scholar, ResearchGate and African Journals Online were searched by limiting publication period from January 2005 to October 2020. Data were extracted with a standardized format prepared in Microsoft Excel and exported to Stata 16.0 for analyses. The $I^{2}$ statistic was used to check heterogeneity across the included studies. DerSimonian and Laird random-effects model was applied to estimate pooled prevalence and 95\% confidence interval across studies. Funnel plot symmetry, Begg's test and Egger's regression test were used to determine the presence of publication bias. Subgroup and sensitivity analysis as well as meta-regression were conducted to explore the potential sources of heterogeneity. The study protocol is registered on PROSPERO with reference number: CRD42020213435.
\end{abstract}

Results: In this meta-analysis, a total of 27 studies with 45,811 study participants were included. The pooled prevalence of metabolic syndrome was $23.7 \%$ with substantial heterogeneity $\left(I^{2}=98.2 \% ; P<0.001\right)$. Geographical-based subgroup analysis revealed that the highest prevalence was observed in Australia (27.3\%). As per meta-analysis of 17 studies, the pooled prevalence of metabolic syndrome in female type 1 diabetes patients (25.9\%) was slightly higher than male T1DM patients (22.5\%).

Conclusion: Nearly a quarter of the type 1 diabetes mellitus patients were affected by metabolic syndrome. Therefore, more attention should be paid to the prevention and control of the epidemic and for the reduction of the morbidity and mortality associated with metabolic syndrome among type 1 diabetes mellitus patients.

Keywords: Prevalence, Metabolic syndrome, Type 1 diabetes mellitus, Systematic review, Meta-analysis

\section{Background}

The metabolic syndrome (MetS) also called Syndrome X and Insulin Resistance Syndrome refers to the commonly occurring disorder comprising central obesity, systemic

*Correspondence: rebuma.belete2016@gmail.com

${ }^{1}$ Department of Medical Laboratory Sciences, College of Health and Medical Sciences, Haramaya University, Harar, Ethiopia

Full list of author information is available at the end of the article hypertension, insulin resistance, atherogenic dyslipidemia specifically hypertriglyceridemia and reduced levels of high-density lipoprotein cholesterol [1, 2]. In the general population, MetS increases the risks of cardiovascular disease (CVD), type 2 diabetes mellitus (T2DM), stroke and cardiovascular mortality [3]. The presence of metabolic syndrome components in Type 1 diabetes mellitus (T1DM) patients is frequent and is associated with an increased incidence of chronic complications and 
mortality [4-6]. Studies suggest that numerous risk factors are responsible for metabolic syndrome in T1DM patients including older age, higher body mass index and glycosylated hemoglobin level [7], elevated diastolic blood pressure and waist circumstance [8] and alcohol consumption [5].

A number of expert groups have developed many different types of clinical criteria for the diagnoses of metabolic syndrome, none of which has gained unanimous acceptance. The first proposal came in 1998 from World Health Organization (WHO) [9], followed by the European Group for Study of Insulin Resistance (EGIR) [10]. In 2001, the National Cholesterol Education Program (NCEP) Adult Treatment Panel III (ATP III) devised a definition for the metabolic syndrome [11], which was updated by the American Heart Association and the National Heart Lung and Blood Institute (modified NCEP) in 2005 [12]. Another set of criteria for the clinical diagnosis of metabolic syndrome has been published in 2005 by the International Diabetes Federation (IDF) [13]. In 2009, a Joint Interim Statement (JIS) was agreed and released by many organizations [14]. Although these organizations have proposed measuring the same components, they have suggested different combinations and different cut-off points. Therefore, the prevalence of MetS varies according to the diagnostic criteria used (Table 1).

The prevalence of the metabolic syndrome ranges from 20 to $25 \%$ in the adult population $[15,16]$ and 0 to $19.2 \%$ [17] in children; but it can reach almost $80 \%$ in type 2 diabetes patients [18]. Previous studies reported that the prevalence of MetS in T1DM patients varies between $3.2 \%$ in Poland [19] and 57.1\% in Finland [20] depending on the study population characteristics and the diagnostic criteria used [4]. Even though there are review articles published on the prevalence of MetS among T1DM patients $[4,21]$, they failed to quantitatively estimate the overall pooled prevalence. Therefore, this study aimed to estimate the pooled prevalence of metabolic syndrome among patients with type 1 diabetes mellitus.

\section{Methods}

\section{Protocol and registration}

The study protocol is registered on PROSPERO with reference number: CRD42020213435. To ensure scientific rigor, the Preferred Reporting Items for Systematic Reviews and Meta-Analysis (PRISMA) guideline was used [22]. The completed checklist is provided as Additional file 1.

Table 1 The definitions of metabolic syndrome

\begin{tabular}{|c|c|c|c|c|c|c|}
\hline & & WHO [9] & NCEP [11] & Modified NCEP [12] & IDF [13] & JIS [14] \\
\hline \multicolumn{2}{|c|}{ Criteria for diagnosis of MetS } & $\begin{array}{l}\text { Diabetes diagnosis or } \\
\mathrm{FBG} \geq 110 \mathrm{mg} / \mathrm{dL} \\
\text { or } I \mathrm{R} \text { with } \geq 2 \text { of the } \\
\text { following }\end{array}$ & $\begin{array}{l}\text { Presence of any } 3 \text { of } 5 \\
\text { of the following }\end{array}$ & $\begin{array}{l}\text { Presence of any } 3 \text { of } \\
5 \text { of the following }\end{array}$ & $\begin{array}{l}\text { WC: }>94 \mathrm{~cm} \\
\text { (men); }>80 \mathrm{~cm} \\
\text { (women) with the } \\
\text { presence of } \geq 2 \text { of } \\
\text { the following }\end{array}$ & $\begin{array}{l}\text { Presence of any } 3 \text { of } 5 \\
\text { of the following }\end{array}$ \\
\hline Hyperglycemia & Fasting glucose & Already required & $\geq 110 \mathrm{mg} / \mathrm{dl}$ & $\begin{array}{l}\geq 100 \mathrm{mg} / \mathrm{dL} \text { or on } \\
\text { Rx for elevated } \\
\text { glucose }\end{array}$ & $\begin{array}{l}\geq 100 \mathrm{mg} / \mathrm{dl} \text { or diag- } \\
\text { nosed diabetes }\end{array}$ & $\begin{array}{l}\geq 100 \mathrm{mg} / \mathrm{dl} \text { or diag- } \\
\text { nosed diabetes }\end{array}$ \\
\hline \multirow[t]{2}{*}{ Dyslipidemia } & TG: & $>150 \mathrm{mg} / \mathrm{dl}$ & $\geq 150 \mathrm{mg} / \mathrm{dl}$ & $\begin{array}{l}\geq 150 \mathrm{mg} / \mathrm{dL} \text { or on } \\
\text { TG Rx }\end{array}$ & $\begin{array}{l}\geq 150 \mathrm{mg} / \mathrm{dl} \text { or on } \\
\text { TG Rx }\end{array}$ & $\begin{array}{l}\geq 150 \mathrm{mg} / \mathrm{dl} \text { or on } \\
\text { TG Rx }\end{array}$ \\
\hline & HDL-C: & $\begin{array}{l}\mathrm{M}:<35 \mathrm{mg} / \mathrm{dl} \\
\mathrm{F}:<40 \mathrm{mg} / \mathrm{dl}\end{array}$ & $\begin{array}{l}\mathrm{M}:<40 \mathrm{mg} / \mathrm{dl} \\
\mathrm{F}:<50 \mathrm{mg} / \mathrm{dl} \text { or on } \\
\text { HDL-C Rx }\end{array}$ & $\begin{array}{l}\mathrm{M}: \leq 40 \mathrm{mg} / \mathrm{dL} \\
\mathrm{F}: \leq 50 \mathrm{mg} / \mathrm{dL} \text { or on } \\
\text { HDL-C Rx }\end{array}$ & $\begin{array}{l}\mathrm{M}:<40 \mathrm{mg} / \mathrm{dl} \\
\mathrm{F}:<50 \mathrm{mg} / \mathrm{dl} \text { or on } \\
\mathrm{HDL}-\mathrm{CRx}\end{array}$ & $\begin{array}{l}\mathrm{M}:<40 \mathrm{mg} / \mathrm{dl} \\
\mathrm{F}:<50 \mathrm{mg} / \mathrm{dl} \text { in } \\
\text { women or on HDL-C } \\
\mathrm{Rx}\end{array}$ \\
\hline Hypertension & Blood pressure & $\geq 140 / 90 \mathrm{mmHg}$ & $\geq 130 / 85 \mathrm{mmHg}$ & $\begin{array}{l}\text { SBP: } \geq 130 \mathrm{mmHg} \text { or } \\
\mathrm{DBP}: \geq 85 \mathrm{mmHg} \text { or } \\
\text { on hypertension Rx }\end{array}$ & $\begin{array}{l}\text { SBP: } \geq 130 \mathrm{mmHg} \text { or } \\
\mathrm{DBP}: \geq 85 \mathrm{mmHg} \text { or } \\
\text { on hypertension Rx }\end{array}$ & $\begin{array}{l}\text { SBP: } \geq 130 \mathrm{mmHg} \text { or } \\
\text { DBP: } \geq 85 \mathrm{mmHg} \text { or } \\
\text { on hypertension Rx }\end{array}$ \\
\hline \multirow[t]{2}{*}{ Obesity } & WC & & $\begin{array}{l}M:>102 \mathrm{~cm} \\
F:>88 \mathrm{~cm}\end{array}$ & $\begin{array}{l}M: \geq 102 \mathrm{~cm} \\
F: \geq 88 \mathrm{~cm}\end{array}$ & Already required & Ethnic dependent \\
\hline & Waist/hip ratio: & $\begin{array}{l}\mathrm{M}:>0.9 \\
\mathrm{~F}:>0.85 \text { or } \\
\mathrm{BMl}>30 \mathrm{~kg} / \mathrm{m}^{2}\end{array}$ & & & & \\
\hline \multicolumn{2}{|l|}{ Other } & $\mathrm{UAE} \geq 20 \mu \mathrm{g} / \mathrm{min}$ & & & & \\
\hline
\end{tabular}

BMI: body mass index; DBP: diastolic blood pressure; F: female; FBG: fasting blood glucose; HDL-C: high density lipoprotein cholesterol; IDF: International Diabetes Federation; IR: insulin resistance; JIS: Joint Interim Statement; M: male; NCEP: National Cholesterol Education Program; Rx: treatment; SBP: systolic blood pressure; TG: triglyceride; UAE: urinary albumin excretion; WHO: World Health Organization; WC: waist circumstance 


\section{Search strategy}

The searches were carried out in Medline via PubMed, CINAHL, ScienceDirect, OVID and other supplementary sources including Google Scholar, ResearchGate and African Journals Online (AJOL). Advanced search strategies were applied in major databases. We used the following key search terms: "metabolic syndrome", "syndrome $\mathrm{X}$ ", "insulin resistance syndrome", "type 1 diabetes", "autoimmune diabetes", "insulin dependent diabetes" and "double diabetes". The key terms were used in combination using Boolean operators like "OR" or "AND" (see Additional file 2). We also added a hand-search of bibliographies of the included studies for additional references and grey literature. Articles published in subscription based journals were accessed through HINARI. The date of the final search for literatures was October 16, 2020.

\section{Study selection}

All observational studies that reported prevalence of metabolic syndrome among T1DM patients and fulfilled the following criteria were entered into the analysis: (1) original studies; (2) human studies; (3) published between January 1, 2005, and October 16, 2020. Non-English articles were also included by translating using Google translate. Studies were excluded if: (1) not fully accessible; (2) possessed a poor quality score as per the stated criteria; (3) duplicate studies, short communications, case reports, conference abstracts, and letters to editors and/or (4) failed to measure the desired outcome of interest.

The presence of MetS in the individual studies was considered if defined according to one of the following mostly accepted criteria; (1) JIS; (2) IDF; (3) modified NCEP; (4) NCEP and (5) WHO (Table 2). Furthermore, if more than one diagnostic criteria of MetS were used in a study, the first choice was the JIS followed by IDF.

Articles that fulfilled inclusion criteria were imported into Endnote9 citation manager. After deleting duplicate records between different bibliographic databases, the remaining titles and abstracts were independently reviewed by two authors (RB and ZA) to identify potentially eligible articles that required a full appraisal. In cases of multiple publications from the same study or overlapping data, preference was given to the most recent one or the one with the most inclusive information. Consensus was achieved for any discrepancies in study eligibility selection through discussion with other authors (AA and or MS).

\section{Data extraction and quality assessment}

Data from the selected studies were recorded into the pre-prepared MS Excel extraction form (see Additional file 3 ). For each included study, the following data were extracted: first author, publication year, country, mean age, mean diabetes duration, study design, study participants, MetS diagnostic criteria, and outcome of interest (MetS cases and prevalence of MetS). Data not presented in the articles were accessed by contacting the corresponding author or, if possible, were calculated from the available data. The methodological quality of each included study was assessed using the modified Newcastle-Ottawa scale (see Additional file 4) [23]. Each article's quality was graded as 'high' if score 8-10; 'moderate' if score 5-7; and 'low' if score $<5$ points. Studies were included in the analysis if they scored $\geq 5$ out of 10 points.

Furthermore, data extraction and quality checks were independently performed by two authors ( $\mathrm{RB}$ and $\mathrm{AA}$ ). Any disagreements were resolved by discussion and if that fails, other authors (ZA and MS) called on to adjudicate the final judgments.

\section{Statistical analysis}

Meta-analysis using DerSimonian and Laird randomeffects model was utilized to obtain the pooled prevalence of metabolic syndrome among T1DM due to expected heterogeneity among studies. The pooled effect size (i.e. prevalence) with a $95 \%$ confidence interval (CI) was generated and presented using a forest plot. Heterogeneity between studies was assessed using the Cochran's $\mathrm{Q}$ and $\mathrm{I}^{2}$ statistic. $\mathrm{I}^{2}$ values of $25 \%, 50 \%$, and $75 \%$ were considered to represent low, moderate and high heterogeneity, respectively [24]. Potential sources of heterogeneity were investigated by subgroup and meta-regression analysis. In addition, potential outliers were investigated in a sensitivity analysis by omitting each study at a time. We also used Funnel plot symmetry, Egger's regression test and Begg's test for evaluating the possibility of publication bias $[25,26]$. P-value $<0.05$ was considered statistically significant. All statistical analyses were performed using Stata/MP 16.0 (StataCorp, College Station, TX, USA).

\section{Results}

\section{Search results}

Our comprehensive search strategy owns us a total of 3459 articles. Of these, 445 from Medline via PubMed, 1637 from ScienceDirect, 669 from CINAHL, 737 were from Ovid interface and 54 were found through a manual search. After excluding duplicate publications, 1672 articles remained. About 1615 articles were excluded after reading the titles and abstracts based on the pre-defined eligibility criteria. Out of them 57 articles were screened for further assessment. Finally, 27 articles were included in the synthesis and analysis (Fig. 1). 


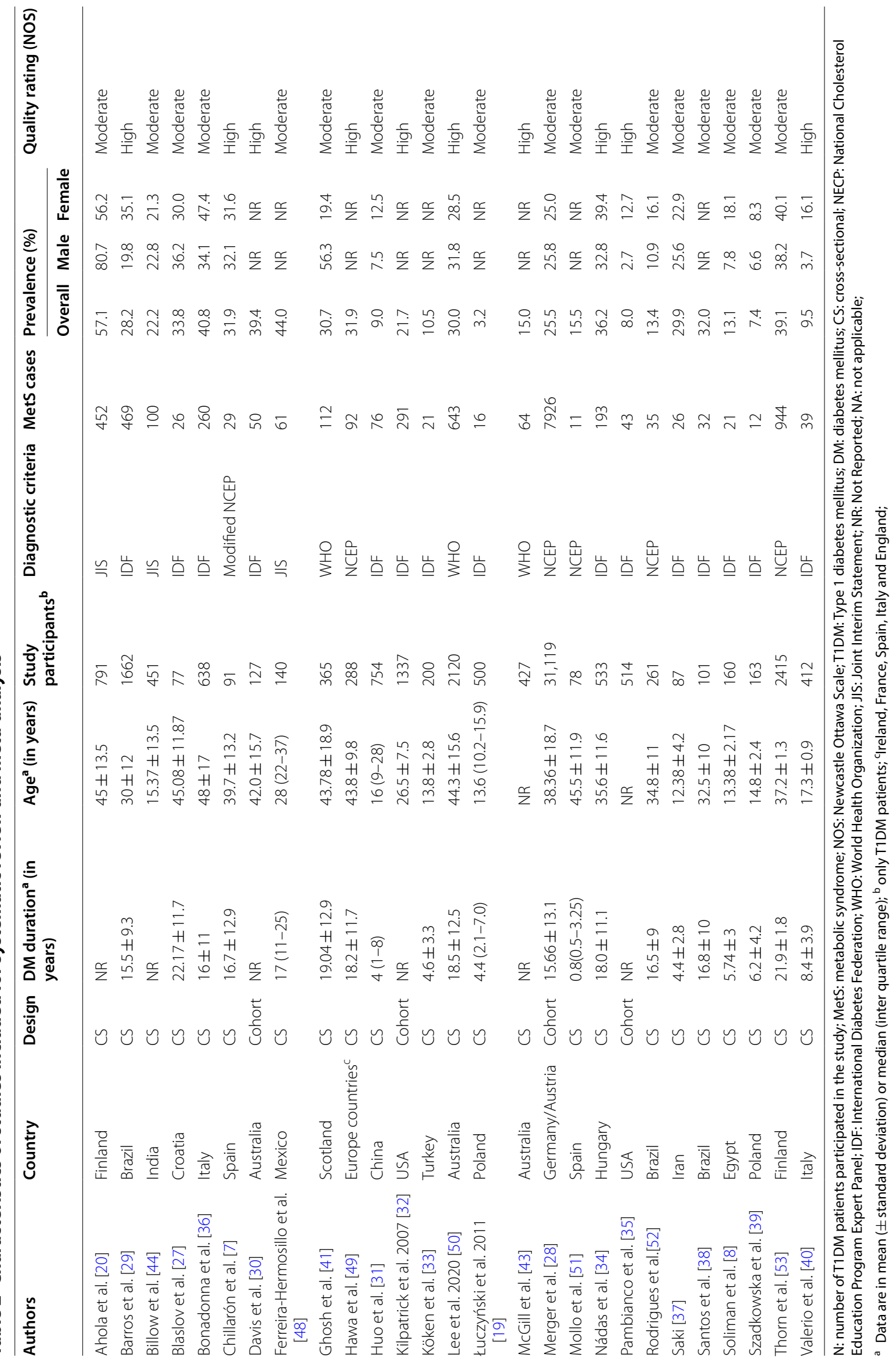




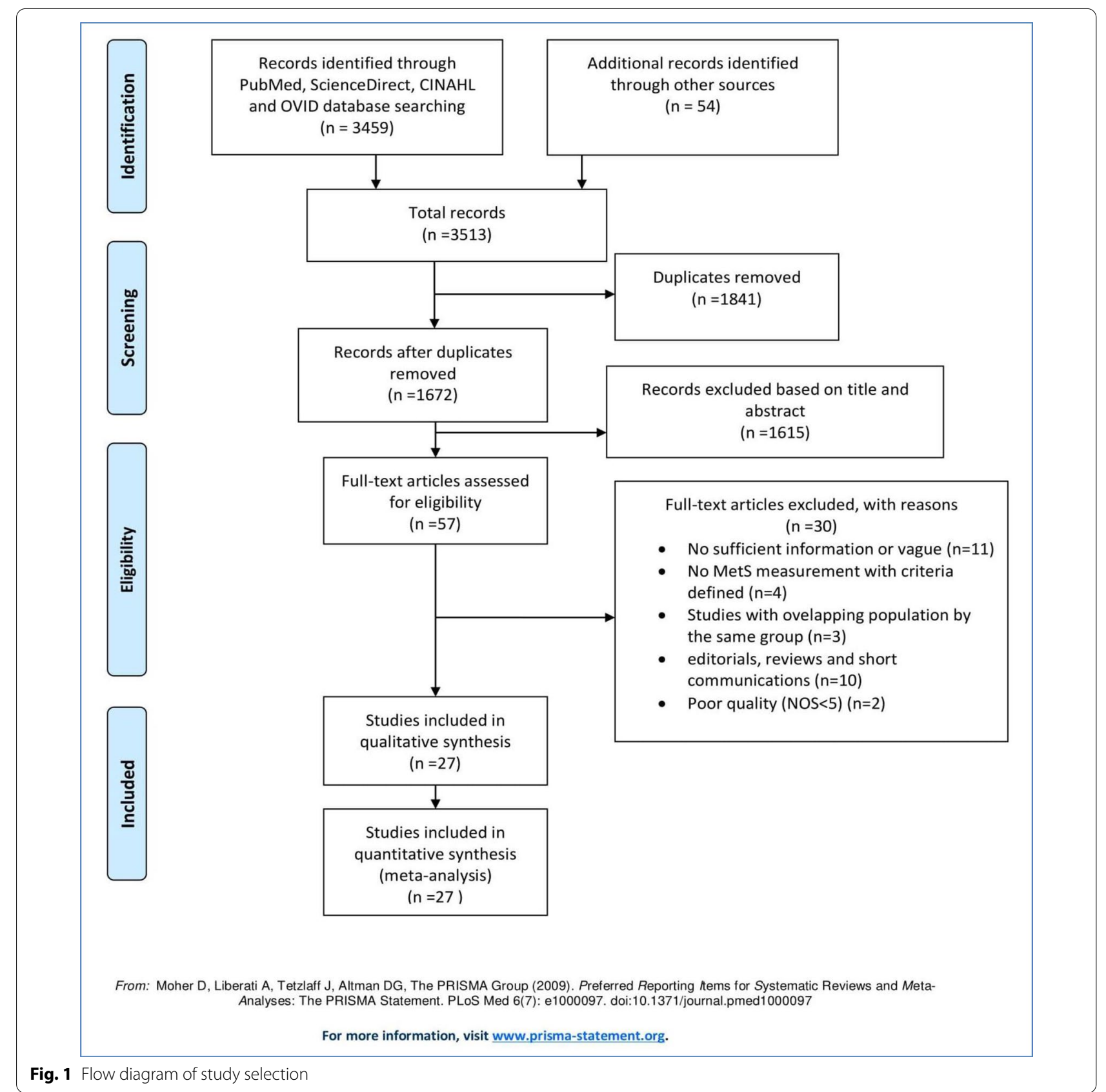

\section{Baseline characteristics of the included studies}

From the studies included in the final analysis, 23 (85.2\%) of them were cross-sectional and 7 (14.8\%) were prospective cohort studies. The sample size of the included studies ranged from 77 [27] to 31,119 [28] with a total number of 45,811 participants. Twenty three countries were represented in this review. Most of the studies were reported from Europe 13 (48.1\%) followed by Asia 4 (14.8\%). The rest were reported from South America 3 (11.1\%), North America 3 (11.1\%), Australia 3 (11.1\%) and Africa 1 (3.7\%). In terms of diagnostic criteria, a total of 15 studies [8, 19, 27, 29-40] used IDF, 5 studies [24, 37-40] used NCEP, 3 studies [41-43] used WHO, 3 studies [20, 44, 45] used JIS and 1 study [7] used modified NCEP (Table 2).

\section{Prevalence of metabolic syndrome}

The overall pooled prevalence of MetS among patients with T1DM was $23.7 \%$ (95\% CI: 19.8, 27.8) with substantial heterogeneity $\left(\mathrm{I}^{2}=98.2 \%\right.$; $\mathrm{P}$ value of $\left.<0.001\right)$. 
Individual study prevalence estimates ranged from 3.2 to $57.1 \%$ whereas studies individual weight was from 3.25 to 3.97\%. Figure 2 presents the Forest Plot derived from the meta-analysis.

\section{Prevalence of metabolic syndrome by gender}

Seventeen studies $(\mathrm{N}=40,493)$ had separate data on the prevalence of MetS for males and females. The pooled prevalence for males was $22.5 \%$ (95\%: CI 16.7 to $28.9 \%$ ) (Fig. 3) while, it was $25.9 \%$ (95\% CI: 20.5 to 31.6\%) for females (Fig. 4). A significant heterogeneity was found in both males $\left(\mathrm{I}^{2}=97.7 \% ; \mathrm{P}<0.001\right)$ and females $\left(\mathrm{I}^{2}=97.0 \%\right.$; $\mathrm{P}<0.001)$.

\section{Subgroup and sensitivity analysis}

To identify the source of heterogeneity across the included studies, subgroup analyses were done for publication year, study design, geographical region, diagnostic criteria, and sample size. Time based subgroup revealed that the prevalence of MetS from 2015 to October 2020 (26.6\%) was higher when compared with 2005 to 2014 (21.8\%) whereas the results of subgroup analysis based on geographical region showed the highest prevalence was from Australia (27.3\%) and the least was from Africa (13.1\%). Another subgroup analysis with diagnostic criteria showed the highest prevalence, $40.5 \%$ (95\% CI 17.7, 65.6), of MetS was observed with JIS whereas the lowest, $19.8 \%$ (95\% CI 13.6, 26.8), was observed with IDF. Furthermore, the pooled prevalence of MetS in studies conducted by cross sectional and cohort study design was $24.0 \%$ (95\% CI $18.3,30.1)$ and $22.2 \%$ (95\% CI 14.9 , $30.4)$ respectively. Results of the subgroup analysis are depicted in Table 3.

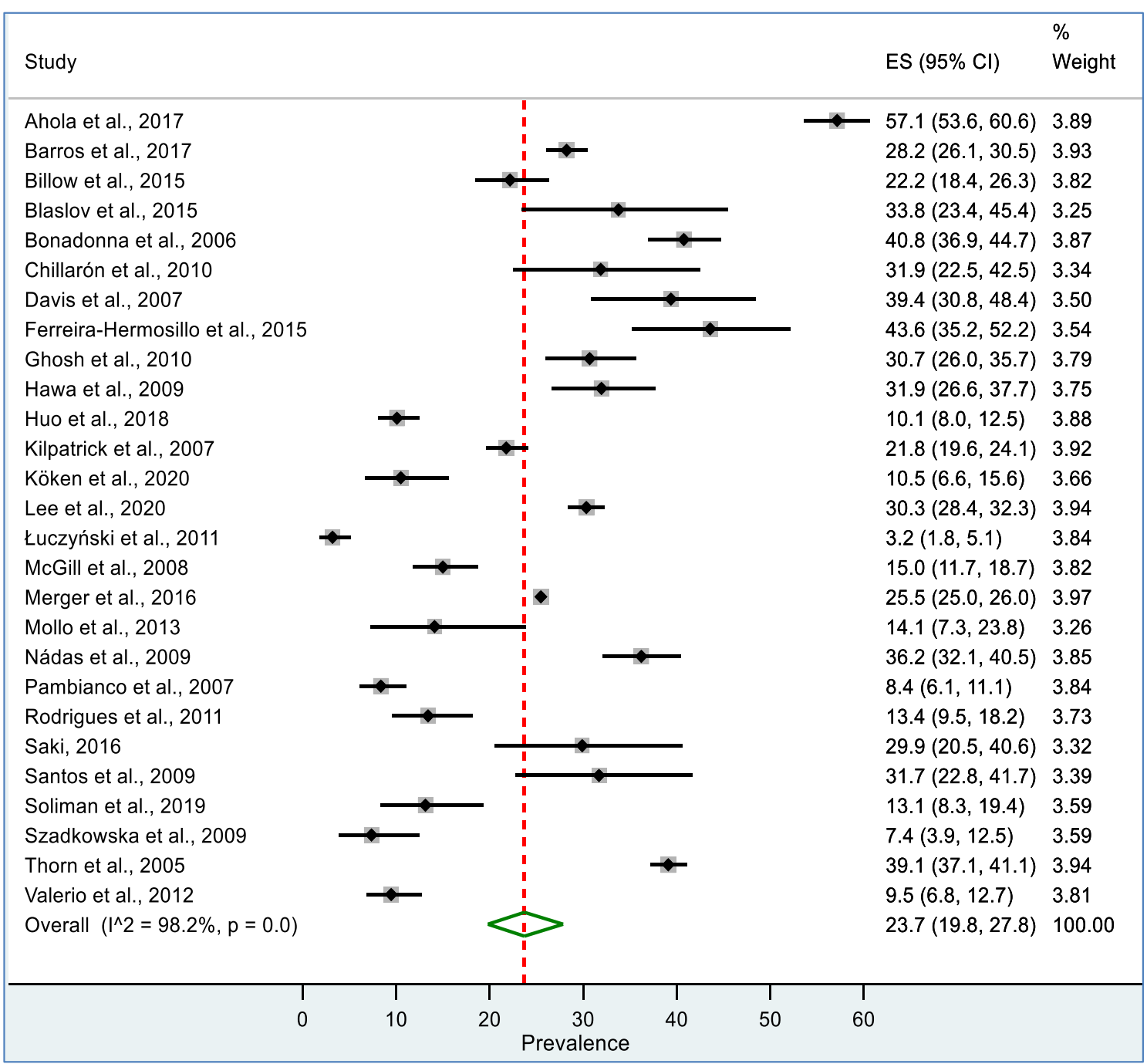

Fig. 2 Forest plot of showing pooled prevalence of MetS among patents with T1DM 


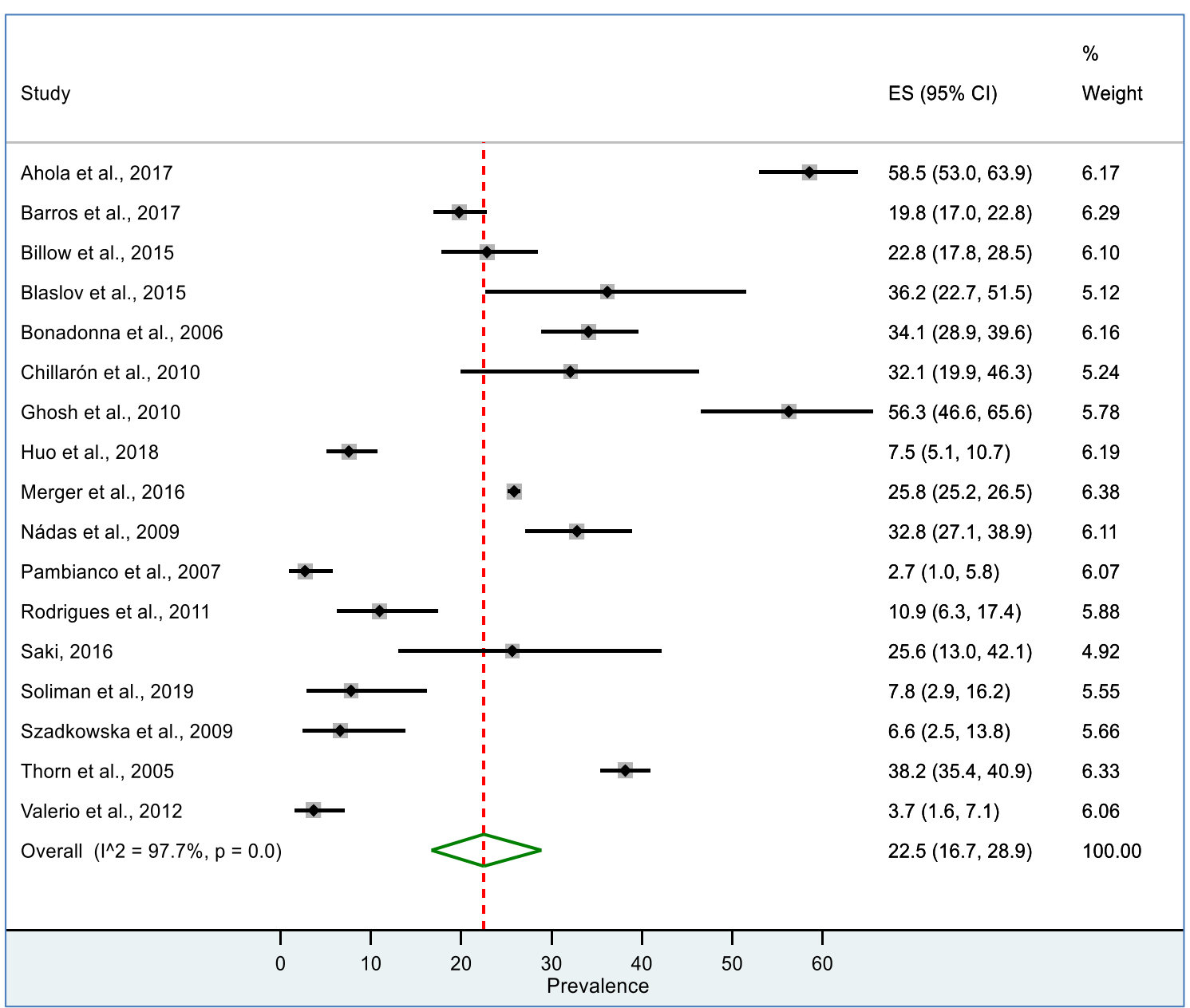

Fig. 3 Forest plot of showing pooled prevalence of MetS among male T1DM patents

To identify a single study influence on the overall meta-analysis, sensitivity analysis using the leave-oneout approach was performed and the result showed that there was no strong evidence for the effect of a single study on the overall meta-analysis result (Fig. 5). To further explore the heterogeneity observed in the study, we carried out meta-regression. Univariate meta-regression revealed that publication year (regression coefficient $=0.99$; $\mathrm{P}$-value $=0.77$ ) and sample size (regression coefficient $=1.00$; P-value $=0.71$ ) are not a source of heterogeneity (Fig. 6).

\section{Publication bias}

The funnel plot (Fig. 7) was symmetric and Egger's regression test $(P=0.87)$ as well as Begg's test $(P=0.90)$ provided no evidence of publication bias.

\section{Discussion}

To the best of our knowledge, this study is the first of its kind to quantitatively pool the prevalence of MetS among T1DM. Meta-analysis of 27 original studies with 45,811 study participants showed that approximately $23.7 \%$ of patients with T1DM had MetS. As per metaanalysis of 17 studies, the pooled prevalence of MetS in female T1DM patients (25.9\%) was slightly higher than male T1DM patients (22.5\%). High degrees of variability of prevalence of MetS among patients with T1DM were reported in studies included in this meta-analysis. The highest prevalence of MetS was reported in Finland (57.1\%) (20) whereas the lowest prevalence was reported in Poland (3.2\%) [19]. This variation might be due to differences in diagnostic criteria used [46], study design, sample size and characteristics of the population participated in the studies. 


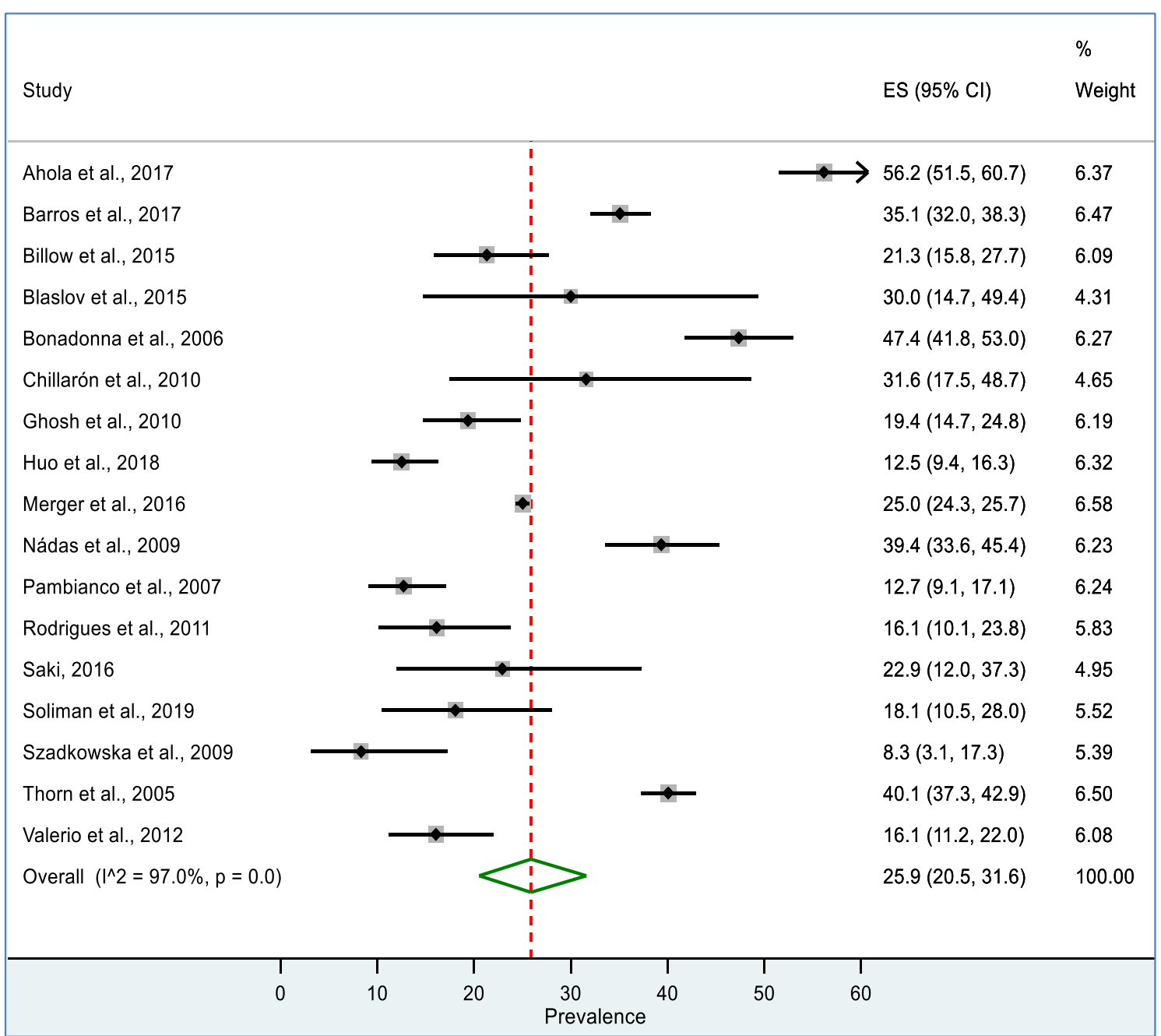

Fig. 4 Forest plot of showing pooled prevalence of MetS among female T1DM patents

The results of subgroup analysis based on geographical region showed that the highest prevalence was from Australia (27.3\%) and the least was from Africa (13.1\%). The possible explanations for this variation might be due to socioeconomic and sociocultural differences between the populations. Another possible explanations for this variation might be differences in the diagnosis definition used, incomparable number of studies from regions and variations in the prevalence of MetS in the general population of the respective regions.

Time- based subgroup revealed that the prevalence of MetS from 2015 to October 2020 (26.6\%) was higher when compared with 2005 to 2014 (21.8\%). This could indicate the increasing trend of MetS among type $1 \mathrm{DM}$ patients worldwide. This increased prevalence probably due to the rising prevalence of MetS as a result of the obesity epidemic in the general population [47]. Consistent with our result, a study conducted in United Kingdom indicated a significant increasing trend of MetS among T1DM patients [32].

Of the five definitions used by studies included in this review, the estimated prevalence was highest based on JIS (40.5\%) and lowest based on IDF consensus (19.8\%). This high discrepancy may be due to abdominal obesity criteria which is not mandatory in JIS definition. Similar findings in variation of MetS prevalence per diagnostic criteria were also reported in many studies conducted in different corners of the world [30, 33-36, 38, 46]. To 
Table 3 Subgroup meta-analysis of metabolic syndrome prevalence among Type 1 diabetes mellitus patients

\begin{tabular}{|c|c|c|c|c|c|c|c|}
\hline \multirow[t]{2}{*}{ Subgroup } & \multirow[t]{2}{*}{ No. of studies } & \multirow[t]{2}{*}{ Sample size } & \multirow[t]{2}{*}{ Prevalence $(95 \% \mathrm{Cl})$} & \multicolumn{4}{|c|}{ Heterogeneity } \\
\hline & & & & $Q$ value & df & $P$ value & $1^{2}$ \\
\hline \multicolumn{8}{|l|}{ Publication year } \\
\hline 2005-2014 & 16 & 8250 & $21.8(15.1,29.4)$ & 870.3 & 15 & $<0.001$ & $98.3 \%$ \\
\hline 2015-2020 & 11 & 37,561 & $26.6(20.8,32.7)$ & 566.5 & 10 & $<0.001$ & $98.2 \%$ \\
\hline \multicolumn{8}{|l|}{ Study design } \\
\hline Cross-sectional & 23 & 12,714 & $24.0(18.3,30.1)$ & 1258.6 & 22 & - & $98.3 \%$ \\
\hline Cohort & 4 & 33,097 & $22.2(14.9,30.4)$ & 131.3 & 3 & - & $97.7 \%$ \\
\hline \multicolumn{8}{|c|}{ Geographical region } \\
\hline Europe & 13 & 37,470 & $26.2(19.3,33.7)$ & 994.8 & 12 & $<0.001$ & $98.8 \%$ \\
\hline North America & 3 & 1991 & $22.6(9.5,39.4)$ & - & 2 & - & - \\
\hline South America & 3 & 2024 & $23.7(13.6,35.6)$ & - & 2 & - & - \\
\hline Asia & 4 & 1492 & $17.0(9.5,26.1)$ & 46.9 & 3 & $<0.001$ & $93.6 \%$ \\
\hline Australia & 3 & 2674 & $27.3(15.7,40.7)$ & - & 2 & - & - \\
\hline Africa & 1 & 160 & $13.1(8.3,19.4)$ & - & 0 & - & - \\
\hline \multicolumn{8}{|l|}{ Sample size } \\
\hline$\leq 300$ & 12 & 1773 & $23.8(16.6,31.8)$ & 154.0 & 11 & $<0.001$ & $92.9 \%$ \\
\hline$>300$ & 15 & 44,038 & $23.7(18.7,29.2)$ & 1271.4 & 14 & $<0.001$ & $98.9 \%$ \\
\hline \multicolumn{8}{|l|}{ Diagnostic criteria } \\
\hline $\mathrm{WHO}$ & 3 & 2912 & $25.0(15.9,35.4)$ & & 2 & - & - \\
\hline NCEP & 5 & 34,161 & $24.8(17.3,33.1)$ & 231.1 & 4 & $<0.001$ & $98.3 \%$ \\
\hline Modified NCEP & 1 & 91 & $31.9(22.5,42.5)$ & - & 0 & - & - \\
\hline IDF & 15 & 7265 & $19.8(13.6,26.8)$ & 666.0 & 14 & $<0.001$ & $97.9 \%$ \\
\hline JIS & 3 & 1382 & $40.5(17.7,65.6)$ & & 2 & - & - \\
\hline
\end{tabular}

solve this problem, an internationally accepted practical and uniform definition of MetS has to be established.

This systematic review and meta-analysis indicates that diabetic patients are facing an epidemic of MetS, and thus, clinicians should pay more attention to the cardiometabolic profiles of diabetic patients and develop targeted strategies against components and risk factors of MetS. We hope that the findings of the current review provide valuable information to the policymakers, National Health Bureaus and other concerned bodies about global and regional prevalence of MetS among T1DM patients. These also can be used for future complementary researches.

\section{Limitations of the study}

This study has a few potential important limitations. First of all, different types of definitions used to diagnose MetS in the included studies may affect the calculation of the pooled prevalence. Additionally, studies from developing countries are rare, which will impact the estimation of the average prevalence of MetS globally. Furthermore, there is substantial heterogeneity observed between studies that may affect the interpretation of the results. Sources of heterogeneity might be from age category and diabetes duration as well as insulin dose which were not investigated due to the incomplete data contained in original articles. 
Meta-analysis estimates, given named study is omitted । Lower Cl Limit OEstimate

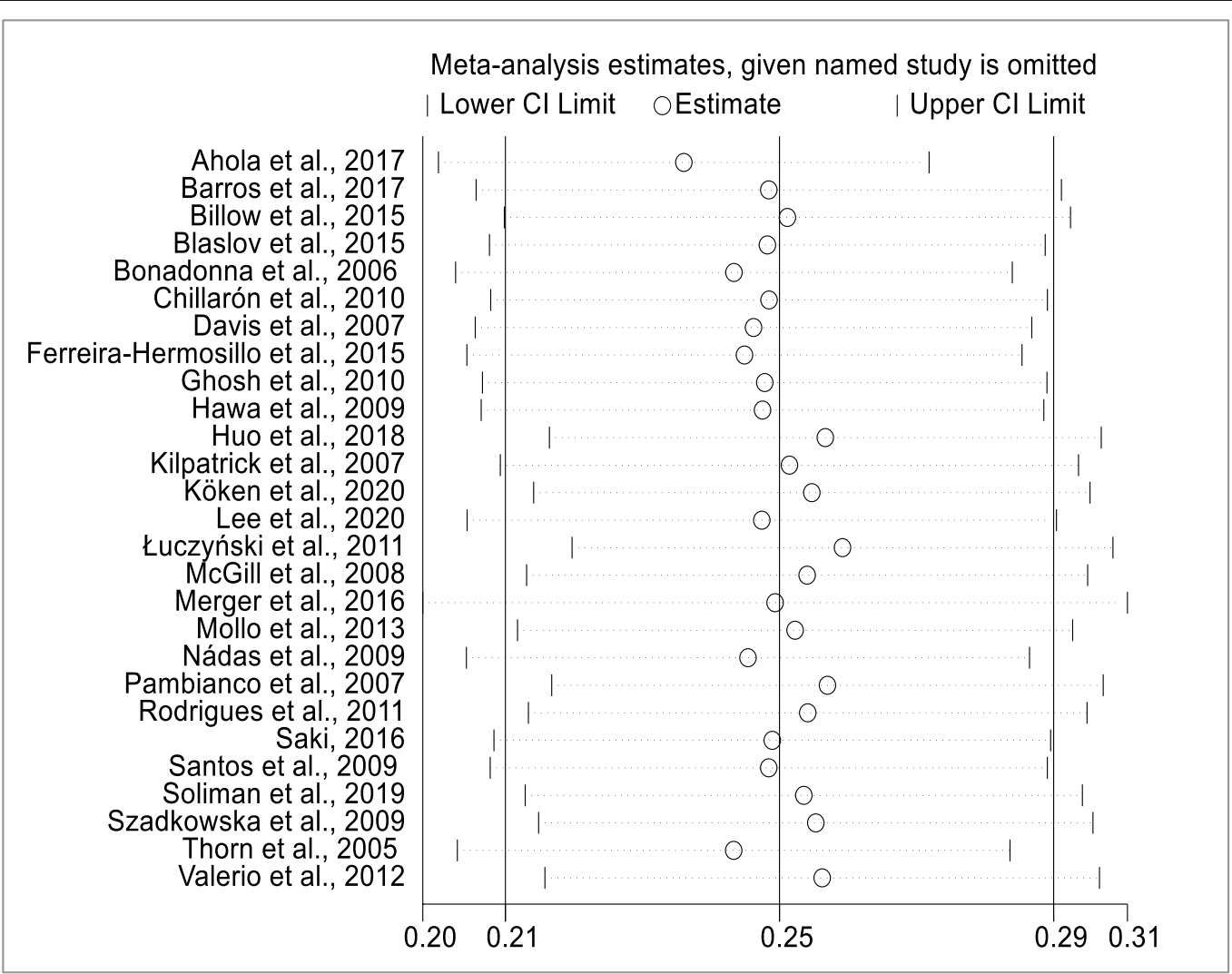

Fig. 5 Results of sensitivity analysis 


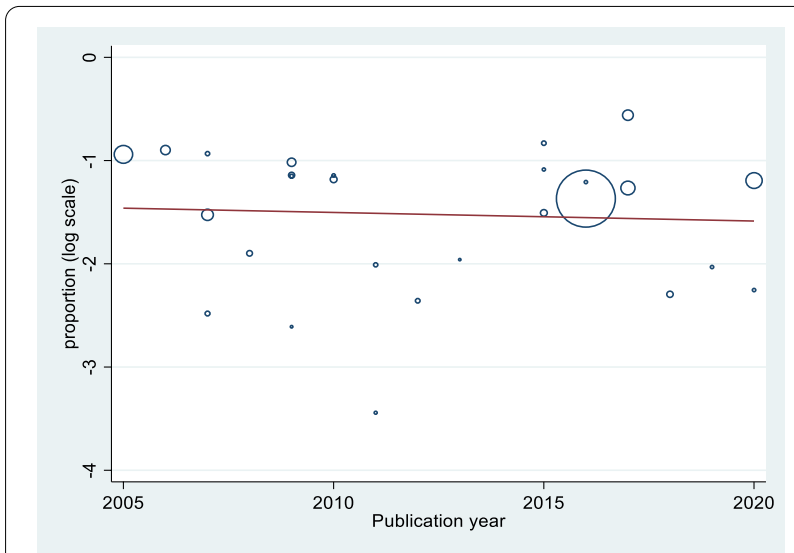

a

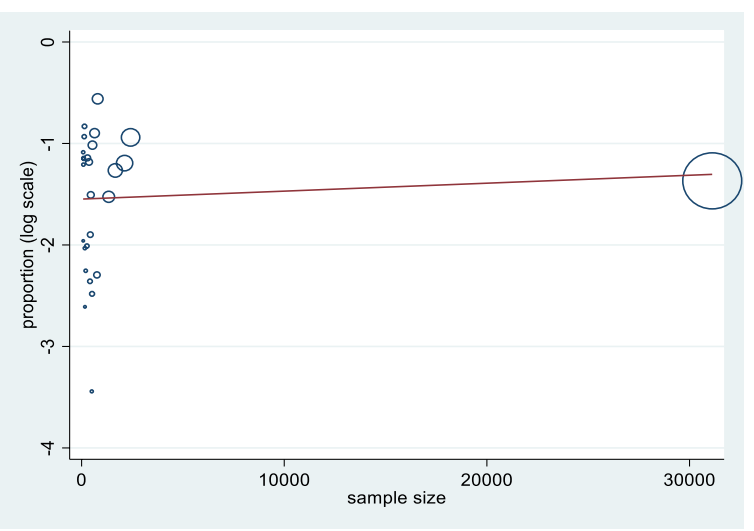

b

Fig. 6 Univariate meta-regression model using a publication year $\mathbf{b}$ sample size

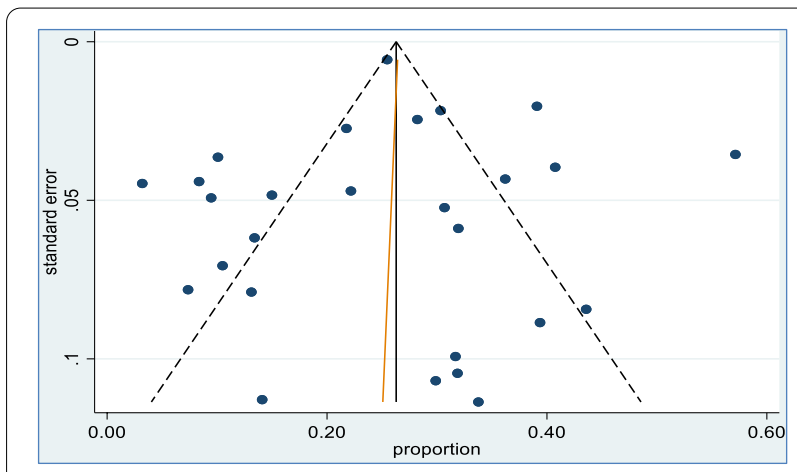

Fig. 7 Publication bias using funnel plot

\section{Conclusion}

Nearly a quarter of the T1DM patients were affected by MetS. Therefore, more attention should be paid to the prevention and control of MetS to ameliorate a further increase in the epidemic and for the reduction of the morbidity and mortality associated with MetS among T1DM patients.

\section{Supplementary Information}

The online version contains supplementary material available at https://doi. org/10.1186/s13098-021-00641-8.

Additional file 1. Completed PRISMA checklist.

Additional file 2. Search strategy.

Additional file 3. Extracted data

Additional file 4. Quality assessment score.

\section{Abbreviations}

DM: Diabetes mellitus; IDF: International Diabetes Federation; MetS: Metabolic syndrome; T1DM: Type 1 diabetes mellitus; NCEP: National Cholesterol Education Program; NOS: Newcastle Ottawa Scale; WHO: World Health Organization; JIS: Joint Interim Statement.

\section{Acknowledgements}

Not applicable.

\section{Authors' contributions}

$\mathrm{RB}, \mathrm{MS}$ and $\mathrm{AA}$ determined the search strategy. RB and ZA conducted the selection of relevant studies separately. $R B$ and $A A$ extracted data and evaluate quality of each study. RB, ZA and MS did the analyses. RB, MS and AA drafted the manuscript. All authors read and approved the final manuscript.

\section{Funding}

Not applicable.

\section{Availability of data and materials}

The datasets supporting the conclusions of this article are included within the article and its additional files.

\section{Ethics approval and consent to participate}

Not applicable.

\section{Consent for publication}

Not applicable.

\section{Competing interests}

The authors declare that they have no competing interests.

\section{Author details}

${ }^{1}$ Department of Medical Laboratory Sciences, College of Health and Medical Sciences, Haramaya University, Harar, Ethiopia. ${ }^{2}$ School of Medicine, College of Health and Medical Sciences, Haramaya University, Harar, Ethiopia.

Received: 24 November 2020 Accepted: 17 February 2021

Published online: 02 March 2021

\section{References}

1. Alberti KGMM, Zimmet P, Shaw J. Metabolic syndrome-a new worldwide definition: a consensus statement from the International Diabetes Federation. Diabet Med. 2006;23:469-80.

2. Mccracken E, Monaghan M, Sreenivasan S. Pathophysiology of the metabolic syndrome. Clin Dermatol. 2018;36(1):14-20.

3. Cankurtaran M, Halil M, Balam B, Dagli N. Prevalence and correlates of metabolic syndrome (MS) in older adults. Arch Gerontol Geriatr. 2006:42:35-45.

4. Chillarón JJ, Le-Roux JA, Benaiges D, Pedro-Botet J. Type 1 diabetes, metabolic syndrome and cardiovascular risk. Metabolism. 2014:63(2):181-7. 
5. Li X, Cao C, Tang X, Yan X, Zhou H, Liu J, Ji L, Yang X, Zhou Z. Prevalence of metabolic syndrome and its determinants in newly-diagnosed adultonset diabetes in China: a multi-center, cross-sectional survey. Front Endocrinol. 2019;10:661.

6. Sarafidis PA, Nilsson PM. The metabolic syndrome : a glance at its history. J Hypertens. 2006;24:621-6.

7. Chillarón JJ, Flores-le-roux JA, Goday A, Benaiges D, Carrera MJ. Metabolic syndrome and type-1 diabetes mellitus: prevalence and associated factors. Rev Esp Cardiol. 2010;63(4):423-9.

8. Soliman HM, Mosaad YO, Ibrahim A. The prevalence and the clinical profile of metabolic syndrome in children and adolescents with type 1 diabetes. Diabetes Metab Syndr Clin Res Rev. 2019;13:1723-6.

9. Consultation WHO. Definition, diagnosis, and classification of diabetes mellitus and its complications. Geneva: World Health Organization; 1999.

10. Balkau B, Charles MA. Comment on the provisional report from the WHO consultation. European Group for the Study of Insulin Resistance (EGIR). Diabet Med. 1999;16:442-3.

11. National Cholesterol Education Program (NCEP) Expert Panel on Detection, Evaluation, and Treatment of High Blood Cholesterol in Adults (Adult Treatment Panel III). Third report of the national cholesterol education program (NCEP) expert panel on detection. Circulation. 2002;106:3143-421.

12. Grundy SM, Cleeman JI, Daniels SR, Donato KA, Eckel RH, Franklin BA, et al. Diagnosis and management of the metabolic syndrome: an American Heart Association/National Heart, Lung, and Blood Institute scientific statement. Circulation. 2005;112:2735-52.

13. IDF Epidemiology Task Force Consensus Group. International Diabetes Federation: The IDF consensus worldwide definition of the metabolic syndrome. [Accessed 25 September 2020]. Available from: https://www. idf.org/component/attachments/attachments.html?id=705\&task=downl oad.

14. Alberti KGMM, Eckel RH, Grundy SM, Zimmet PZ, Cleeman Jl, Donato KA, et al. Harmonizing the metabolic syndrome: a joint interim statement of the International Diabetes Federation Task Force on Epidemiology and Prevention; National Heart, Lung, and Blood Institute; American Heart Association; World Heart Federation; International Atherosclerosis Society; and International Association for the Study of Obesity. Circulation. 2009;120:1640-5.

15. Ranasinghe P, Mathangasinghe Y, Jayawardena R, Hills AP, Misra A. Prevalence and trends of metabolic syndrome among adults in the asia-pacific region: a systematic review. BMC Public Health. 2017;17(101):1-9.

16. do Vale Moreira NC, Hussain A, Bhowmik B, Mdala I, Siddiquee T, Fernandes VO, Jay RM, Meyer HE. Prevalence of metabolic syndrome by different definitions, and its association with type 2 diabetes, pre-diabetes, and cardiovascular disease risk in Brazil. Diabetes Metab Syndr Clin Res Rev. 2020;14(5):1217-24.

17. Friend A, Craig L, Turner S. The prevalence of metabolic syndrome in children: a systematic review of the literature. Metab Syndr Relat Disord. 2013;11(2):71-80.

18. Tan MC, Ng OC, Wong TW, Joseph A, Chan Y, AR Hejar. Prevalence of metabolic syndrome in type 2 diabetic patients: a comparative study using WHO, NCEP ATP III, IDF and Harmonized definitions. Health. 2013;(2013).

19. Łuczyński W, Szypowska A, Głowińska-Olszewska B, Bossowski A. Overweight, obesity and features of metabolic syndrome in children with diabetes treated with insulin pump therapy. Eur J Pediatr. 2011;170:891-8.

20. Ahola AJ, Harjutsalo V, Thorn LM, Freese R, Forsblom C, Mäkimattila $\mathrm{S}$, et al. The association between macronutrient intake and the metabolic syndrome and its components in type 1 diabetes. Br J Nutr. 2017;117(3):450-6.

21. Gingras V, Leroux C, Fortin A, Legault L, Rabasa-Ihoret R. Predictors of cardiovascular risk among patients with type 1 diabetes: a critical analysis of the metabolic syndrome and its components. Diabetes Metab. 2017:43(3):217-22.

22. Moher D, Shamseer L, Clarke M, Ghersi D, Liberati A, Petticrew M, et al. Preferred reporting items for systematic review and meta-analysis protocols ( PRISMA-P) 2015 statement. Syst Rev. 2015:4(1):1-9.

23. Wells GA, Shea B, O'Connell DA, Peterson J, Welch V, Losos M, Tugwell P. The Newcastle-Ottawa Scale (NOS) for assessing the quality if nonrandomised studies in meta-analyses. http://www.ohri.ca/programs/clini cal_epidemiology/oxford.asp. Accessed 19 Oct 2020.
24. Higgins JPT, Thompson SG. Quantifying heterogeneity in a meta-analysis. Stat Med. 2002;21:1539-58.

25. Egger M, Smith GD, Schneider M, Minder C. Bias in meta-analysis detected by a simple, graphical test. BMJ. 1997;315:629-34.

26. Sterne JAC, Gavaghan D, Egger M. Publication and related bias in metaanalysis: power of statistical tests and prevalence in the literature. J Clin Epidemiol. 2000;53:1119-29.

27. Blaslov K, Bulum T, Zibar K, Duvnjak L. Relationship between metabolic syndrome and meal-induced glucagon like peptide-1 response in type 1 diabetic patients1-1. J Diabetes. 2015;7(3):340-6.

28. Merger SR, Kerner W, Stadler M, Zeyfang A, Jehle P, Müller-Korbsch M, et al. Prevalence and comorbidities of double diabetes. Diabetes Res Clin Pract. 2016;119:48-56.

29. Barros BSV, Santos DC, Pizarro MH, Gomes LG, Brito M. Type 1 diabetes and non-alcoholic fatty liver disease: when should we be concerned? A nationwide study in Brazil. Nutrients. 2017;9:878.

30. Davis TME, Bruce DG, Davis WA. Prevalence and prognostic implications of the metabolic syndrome in community-based patients with type 1 diabetes: the Fremantle Diabetes Study. Diabetes Res Clin Pract. 2007;78(3):412-7.

31. Huo L, Ji L, Deng W, Shaw JE, Zhang P, Zhao F, et al. Age distribution and metabolic disorders in people with type 1 diabetes in Beijing and Shantou, China: a cross-sectional study. Diabet Med. 2018;35(6):721-8.

32. Kilpatrick ES, Rigby AS, Atkin SL. Insulin resistance, the metabolic syndrome, and complication risk in type I diabetes: "double diabetes" in the diabetes control and complications trial. Diabetes Care. 2007:30(3):707-12.

33. Köken ÖY, Kara C. Prevalence of obesity and metabolic syndrome in children with type 1 diabetes: a comparative assessment based on criteria established by the International Diabetes Federation, World Health Organisation and National Cholesterol Education Program. J Clin Res Pediatr Endocrinol. 2020;12(1):55-62.

34. Nádas J, Putz Z, Nyi JF, Gaali Z, Gyimesi A, Neuwirth G, et al. Cardiovascular risk factors characteristic for the metabolic syndrome in adult patients with type 1 diabetes. Exp Clin Endocrinol Diabetes. 2009;117:107-12.

35. Pambianco G, Costacou T, Trevor JO. The prediction of major outcomes of type 1 diabetes: a 12-year prospective evaluation of three separate definitions of the metabolic syndrome and their components and estimated glucose disposal rate. Diabetes Care. 2007;30(5):1248-54.

36. Riccardo B, Cucinotta D, Fedele D, Riccardi G, Tiengo A. The metabolic syndrome is a risk indicator of microvascular and macrovascular complications in diabetes: results from Metascreen, a multicenter diabetes clinic-based survey. Diabetes Care. 2006;29:2701-7.

37. Saki F. Prevalence of metabolic syndrome in children with type 1 diabetes in South of Iran. J Compr Ped. 2016;7(3):e37703.

38. Santos CE, Schrank Y, Kupfer R. Análise crítica dos critérios da OMS, IDF e NCEP para síndrome metabólica em pacientes portadores de diabetes melito tipo 1. Arq Bras Endocrinol Metab. 2009;53(9):1096-102.

39. Szadkowska A, Pietrzak I, Szlawska J, Kozera A, Gadzicka A, Młynarski W. Abdominal obesity, metabolic syndrome in type 1 diabetic children and adolescents. Pediatr Endocrinol Diabetes Metab. 2009;15(4):233-9.

40. Valerio G, lafusco D, Zucchini S, Maffeis C. Abdominal adiposity and cardiovascular risk factors in adolescents with type 1 diabetes. Diabetes Res Clin Pract. 2012;97(1):99-104.

41. Ghosh S, Collier A, Hair M, Malik I, Elhadd T. Metabolic syndrome in type 1 diabetes. Int J Diabetes Mellit. 2010;2:38-42.

42. Lee AS, Twigg SM, Flack JR. Metabolic syndrome in type 1 diabetes and its association with diabetes complications. Diabet Med. 2020;38:e14376.

43. McGill M, Molyneaux L, Twigg SM, Yue DK. The metabolic syndrome in type 1 diabetes: does it exist and does it matter? J Diabetes Complications. 2008;22(1):18-23.

44. Billow A, Anjana RM, Ngai M, Amutha A, Pradeepa R, Jebarani S, et al. Prevalence and clinical profile of metabolic syndrome among type 1 diabetes mellitus patients in southern India. J Diabetes Complicat. 2015;29(5):659-64.

45. Ferreira-hermosillo A, Ramírez-rentería C, Mendoza-zubieta V, Molinaayala MA. Utility of the waist-to-height ratio, waist circumference and body mass index in the screening of metabolic syndrome in adult patients with type 1 diabetes mellitus. Diabetol Metab Syndr. 2014;6(1):32. 
46. Reinehr T, De SG, Toschke M, Andler W. Comparison of metabolic syndrome prevalence using eight different definitions: a critical approach. Arch Dis Child. 2007:92:1067-72.

47. Kassi E, Pervanidou P, Kaltsas G, Chrousos G. Metabolic syndrome: definitions and controversies. BMC Med. 2011;9:48.

48. Ferreira-Hermosillo A, Molina-Ayala M, Ramírez-Rentería C, Vargas G, Gonzalez B, Isibasi A, Archundia-Riveros I, Mendoza V. Inflammatory cytokine profile associated with metabolic syndrome in adult patients with type 1 diabetes. J Diabetes Res. 2015;2015:972073.

49. Hawa MI, Thivolet C, Mauricio D, Alemanno I, Cipponeri E, Collier D, et al. Metabolic syndrome and autoimmune diabetes: action LADA 3. Diabetes Care. 2009;32:160-4.

50. Lee AS, Twigg SM, Flack JR. Metabolic syndrome in type 1 diabetes and its association with diabetes complications. Diabet Med. 2020. https://doi. org/10.1111/dme.14376.

51. Mollo A, Hernandez M, Marsal JR, Esquerda A, Rius F, Blanco-Vaca F, et al. Latent autoimmune diabetes in adults is perched between type 1 and type 2: evidence from adults in one region of Spain. Diabetes Metab Res Rev. 2013;29:446-51.
52. Rodrigues TC, Canani LH, Schvartzman P, Gross JL. Hypertension is the metabolic syndrome component most strongly associated with microvascular complications and coronary artery calcification in Type 1 diabetes. J Endocrinol Invest. 2011;34:e58-63.

53. Thorn LM, Forsblom C, Fagerudd J, Thomas MC, Pettersson-Fernholm K Saraheimo M, et al. Metabolic syndrome in type 1 diabetes: association with diabetic nephropathy and glycemic control (the FinnDiane study). Diabetes Care. 2005;28(8):2019-24.

\section{Publisher's Note}

Springer Nature remains neutral with regard to jurisdictional claims in published maps and institutional affiliations.
Ready to submit your research? Choose BMC and benefit from:

- fast, convenient online submission

- thorough peer review by experienced researchers in your field

- rapid publication on acceptance

- support for research data, including large and complex data types

- gold Open Access which fosters wider collaboration and increased citations

- maximum visibility for your research: over 100M website views per year

At BMC, research is always in progress.

Learn more biomedcentral.com/submissions 